\title{
Testing a Crime Control Model: Does Strategic and Directed Deployment of Police Officers Lead to Lower Crime?
}

\author{
James P. McElvain, ${ }^{1}$ Augustine J. Kposowa, ${ }^{2}$ and Brian C. Gray ${ }^{3}$ \\ ${ }^{1}$ Department of Social Work and Social Ecology, Loma Linda University and Riverside County Sheriff's Department, \\ Riverside, CA, USA \\ ${ }^{2}$ Department of Sociology, University of California, Riverside, CA, USA \\ ${ }^{3}$ LEIU Southwest Zone, Riverside County Sheriff's Department, Riverside, CA, USA
}

Correspondence should be addressed to James P. McElvain; jmcel001@ucr.edu

Received 30 May 2012; Revised 23 September 2012; Accepted 8 October 2012

Academic Editor: Kevin M. Beaver

Copyright (C) 2013 James P. McElvain et al. This is an open access article distributed under the Creative Commons Attribution License, which permits unrestricted use, distribution, and reproduction in any medium, provided the original work is properly cited.

\begin{abstract}
The purpose of the paper was to investigate whether implementation of a crime control model (based, in part, on the concepts of COMPSTAT) in one southern California city was effective in reducing crime. Time series regression models were fitted to data collected from the Riverside County Sheriff's Department, city of Perris, for the years 2000 through 2010. Additional data were collected from three other cities that served as controls. Results showed that the program was effective in reducing crime rates in Perris. The effect remained significant even after taking into account time trends and control cities. Analysis also found that while the program was more effective in lessening total and property crime rates, it was less so for violent crime rates. It was concluded that strategic and directed policing models (e.g., COMPSTAT, hot spot policing, etc.) may be more effective in crime reduction efforts than reactive policing methods.
\end{abstract}

\section{Introduction}

Throughout the history of law enforcement in the United States, the manner in which service has been delivered continues to be a tremendous challenge to overcome. It seems that from one generation to the next, police departments, whether through self-direction or external pressures, have been tasked with managing personnel in such a manner in order to continue to meet a given community's needs, objectives, problems, and directions despite the level of resources made available to them. Typically, each era of policing has come about as a matter of evolution, or what is generally called a period of "reform," in response to a community's expectation of the service being provided. If each generation of reform were to be viewed as a paradigm, the movement from one paradigm to another could be referred to as a "paradigm shift," fueled by a "continued demand for safer, more effective and efficient ways to police communities" ([1], p.53). The purpose of this paper was to investigate whether the introduction of a crime-control model (based in part on the concepts of COMPSTAT) in one southern California city was effective in reducing crime.

\section{Paradigms of Policing-Shifting to a New Model}

One of the first paradigm shifts followed on the heels of political influence and police corruption, which came about in the middle of the 20th century [1-6]. This "professional" model of policing is also recognized as the "rational-legal bureaucratic" model, which valued a centralized and bureaucratic command structure [1]. During the "professional" era, the primary principles associated with this model were the development of technical skills, training, education, and adherence to the role of crime fighting [6]. Measurement for success was nested in crime statistics such as the number of arrests and response times. Officers were expected to gather "just the facts" and patrol their beats in a random fashion between calls for service as a means to deter criminal conduct. 
Given the era and circumstances within the communities and demands on policing, the professional model worked. Between the mid-1900s and into the 1980s our social environment changed, expectations evolved, and, in turn, so did the delivery of police services. In 1968, the President's Commission on Disorder "urged law enforcement to repair its relationship with minority populations and other special interests groups and to "humanize" the behavior of police officers" ([4], p. 70). As a result, policing eventually evolved into what is known as the "community-oriented-policing" era, which did not happen immediately or whole-heartedly by all law enforcement agencies. Some have maintained that community-oriented policing is more talk than action, ineffective, and a mere philosophy that has failed to be actualized by many departments $[1,7-10]$.

Whether police departments embraced the idea of community-oriented policing or not, there was certainly a demand for a higher, more personalized, level of service by the citizens being served. As a summary of this demand and what the expectation looks like at its optimum level of implementation, Walsh and Vito ([1], p. 55) write, “... in its most ideal form, community policing posits that each community or neighborhood area should be policed in accordance with neighborhood needs and values." In other words, each community would receive a personalized delivery of service wherein beat officers cater to the community's crime and quality of life problems as identified by the community itself. For this to occur, officers need to become intimately familiar with the community, neighborhood, business district, and/or enclave he/she patrols on a daily basis.

Despite its political correctness and feel-good collaborative components, community-oriented policing fell short of its overall expectation. Many departments, at best, implemented a watered-down version [7], which proved to be ineffective. For other departments, it became a philosophy that was spoken in public, but never truly translated to action beyond the level of a subunit (e.g., problem-oriented or special enforcement team) of the department [1]. Moreover, one of the greatest weaknesses in this model of policing is due to its strategy, which is "dependent on the lowest, often less experienced members of the police department who are ill prepared to address complex community problems" ([1], p. 57). While crime rates remained high, public fear of victimization continued, and an overall sense that the quality of life in many communities remained low, a new era in policing was developing.

In their analysis of eight cities that implemented community policing programs, Sadd and Grinc [11] found several challenges that limited the success of this innovative style of policing. In part, the difficulties discovered were internal to the culture and perception of the police officers, whereas others were due to external community forces. These challenges included officers' resistance to change, their possession of only an elementary understanding of the principles of community policing despite efforts to train them, and their failure to see how this was related to "real" police work. Commenting on the officers' perception that community policing was another "politically driven" fad, Sadd and Grinc ([11], p. 11) state, "Some took comfort from the fact that a long list of new projects and restructurings had come and gone without significantly changing the way policing is performed." Essentially, there was a lack of acceptance by the officers, and their pessimistic view of community policing was that community policing was not novel, but repackaged the principles of "good, old-fashioned policing" (p. 11). From the perspective of the community, Sadd and Grinc [11] learned that those neighborhoods that could benefit most from the program (i.e., people living in public housing or underprivileged communities) knew little about community policing beyond "picnics, block parties and events for children" (p. 12). Moreover, like those officers who saw community policing as a phase that would soon pass, community members also held a similar point of view and "define community policing as "just another program" in which services are here today but gone tomorrow" ([11], p. 13).

In spite of the efforts made by law enforcement departments in the past, most continue to struggle with an accurate understanding of crime in our society, and more importantly, they fail to recognize their role. Although this paper addresses contemporary issues facing law enforcement, we suggest that the issue is law enforcement's inability, inefficiency to keep pace with emerging best practices, or unwillingness to recognize its responsibility to do everything in its power to provide the best level of service to reduce crime in our communities. Until law enforcement actually embraces this role, its delivery of service will forever remain an existing issue.

\section{The Emergence of the Crime-Control Model}

For some time now, many academics and police practitioners have believed that the police could not control crime $[4,7$, $8,12]$. There are simply too many social forces that cause criminal behavior for the police to have a direct impact. Some naïveté has given way to more recent research and results from the emerging trend in law enforcement. It should be noted that our use of the term "emerging trend" is a loose interpretation because the concept and development of this latest paradigm shift began more than 17 years ago, but is still finding its way into police departments, big and small, across the United States.

Some researchers assert that crime is caused by poverty, racism and economic injustices [13], economic, social, demographic, and ethnographic forces [7], and/or “... social issues, such as poverty, drugs, and unemployment" ([4], p. 3). Explaining why it was believed that the police could not impact crime, McDonald ([4], p. 3) further states, "Police functioned using traditional enforcement methods of arrest, with the belief that although they could impact individual crime patterns through the arrest of an individual, for the most part they were handicapped in being able to change the flow of crime." In spite of this perspective, and with very little empirical evidence, several police executives have taken credit for crime decreases as a result of their policing practices [14]. In their research, Rosenfeld et al. [8] noted that not all administrators are quick to claim credit for a decrease 
in crime. The more cautious executives recognize they will eventually be called upon to explain the increases as well.

While serving as the New York City Police Department Commissioner in the early 1990s, William Bratton set out to implement an innovative strategy for policing. Unlike most of the academics and police managers, Bratton believed that, if done right, the police do impact crime; however, they have been going about it the wrong way. By way of the traditional (i.e., professional) model of policing, which arguably continued into the community-oriented policing era, police primarily operated by following the three Rs of policing: rapid response, random patrols, and reactive investigations $[1,4,7,15]$. Through research, it was observed that random patrol, which was thought to deter crime, merely produced random results [4]. In part, the Kansas City preventive patrol experiment (Kelling et al., [16]) determined that police resources could be better utilized if dedicated to directed crime control strategies as opposed to following the principle of the three Rs. Ultimately, by themselves, the three Rs have demonstrated a failure to effectively prevent or reduce crime, which is the primary, yet often forgotten, mission and responsibility of the police.

Asserting that police had lost sight of their primary role, Bratton and Malinowski ([7], p. 261) state, “... we were encouraged to focus on response to crime and to measure our success by arrest numbers, clearance rates and response time. In effect, we were not held accountable for doing anything to prevent crime." Bratton believed that the "quickest way to impact crime is with a well-led, managed and appropriately resourced police force that embraces risk taking and not risk adversity and a policing structure that includes accountability-focused... management principles..." ([7], p. 261). In order to bring about this change in the delivery of service to coincide with the idea that law enforcement can directly impact and reduce crime Bratton developed a "crime control" model, which is more commonly recognized as "COMPSTAT",

COMPSTAT brings about a change in policing by embracing and incorporating some of the more effective strategies found in both the professional and communityoriented policing models. The basis of the crime control model is premised "on the principle that by controlling serious crime, police are better poised to maintain control and solve other community problems in the promotion of public safety" ([4], p. 1).

\section{Principles of COMPSTAT}

Declared an innovative approach to policing, which continues to spread across the United States in both large and small law enforcement departments, the crime control model is based on five principles: specific objectives, timely and accurate intelligence, effective strategies and tactics, rapid deployment of personnel and resources, and relentless followup and assessment [4]. (Other researchers provide for as few as four and as many as six principles or strategies (e.g., see $[1,8,10,17])$.) Each of these principles lends themselves to a significantly different way of operating for any police department that continues to employ the professional or community-oriented policing models. As such, resistance to change can and will occur, especially with managers, those who are impacted at a greater level with this model [18] Bratton believed that he would gain support for organizational change if there was a sense of "internal crisis" shared with the employees [19]. Quoting Bratton, Long et al. ([19], p. 49) write the following:

Organizations can change the most when they are in crises. When I came to the New York Transit police, it was clear to everyone that the department was in crisis, with crime escalating and morale very low. With the NYPD, we had to create a crisis since there was no crisis of confidence. The prevailing view was that we did things well. We are the best. There is no one any better. So the strategies and reengineering process was intended to create a crisis and process to move the organization through changes... It was revolutionary.

In order to reduce and prevent crime (i.e., the crisis at hand), Bratton instituted a set of management strategies that followed the five principles previously introduced.

One of the shortcomings of community-oriented policing was a lack of specific objectives. Specific objectives such as "decreasing street robberies, youth homicide, drug sales to juveniles, vandalism..." by a set percentage of overall crime sends a "powerful message" to those tasked with carrying out the job ([4], p. 8). Accurate and timely intelligence is key to directing resources where and when crime occurs. Researchers have come to recognize that crime tends to occur in trends in both time and space, which are identified as "hot spots." This means that by collecting, analyzing and disseminating crime data in a timely manner, police officers can be deployed more effectively, which is the rationalization of policing [17]. Crime data and communication amongst principal enforcers is important to understanding how officers need to respond to emerging problems before they grow or lead to further victimization.

The purpose for collecting and analyzing crime data is to create a clear understanding of the problem. With this information in hand, officers can then develop effective tactics and strategic responses to the problem. Departing from the professional and community-oriented policing models, a defined level of accountability is injected into the crime control model. Police managers are empowered (i.e., decentralized decision making) to run their commands all the while maintaining responsibility for results, which tie back into the specific objectives we began with. Accountability within this model occurs through executive oversight by the department head or designee, who reviews crime data, patterns of rises and declines in crime, with the managers on a regular basis to ensure that managers are on track with an appropriate level of understanding of the problem and are effectively addressing it. The reason managers are held accountable is because "they have the ability to allocate resources to make effective tactics a reality" ([8], p. 76). 
Rapid deployment of personnel and resources and relentless followup and assessment coincide with management accountability and data analysis. The objective is to respond to crime and varying trends as they occur. This means that as crime is mapped geographically as close to real time as possible, managers are encouraged to put the "cops on the dots." This should occur on a regular (i.e., weekly to biweekly) basis "because crime is dynamic and trends emerge and dissipate quickly," which can be as a result of the tactics being employed by the officers [20]. (The frequency of analysis may depend on the amount of available information that would add value to the analysis (i.e., number of reported crimes, calls for service, department size, etc.) To be meaningful, there needs to be something to analyze.) Typically, law enforcement managers skip the process of "assessing and evaluating strategies and tactics" used ([4], p. 21). As a result, they remain uninformed as to what did or did not work. Relentless followup and assessment ensures accountability and responsibility on the part of the managers and their staff.

\section{Crime in Time and Space}

Currently, there is little empirical research supporting a link between COMPSTAT, crime reduction and crime displacement. A common assertion found in the literature was that New York City's remarkable decline in crime, without the occurrence of crime displacement to another location, was attributable to COMPSTAT. Commenting on New York City Police Department's implementation of COMPSTAT, Henry ([21], p. 45) states, "no displacement effect occurred-as reflected in the city-wide statistics, overall crime declined dramatically in every one of the agency's seventy-six precincts, and the greatest percentage decreases were found in precincts where the levels of crime and public disorder were the highest."

In review of crime statistics, mapping, and our own personal experiences, most people recognize that crime does not occur evenly throughout our communities. Relying upon the theory of routine activities, we find that for crime to occur, three things need to take place in time and space: first, there needs to be a motivated person to commit crime; second, a suitable target needs to be present; third, there are no capable guardians present to prevent the criminal act from occurring [22]. Nested in the theory is the idea that based upon routine activities, criminal opportunities rise and fall. Using this theoretical framework, researchers have set out to examine the impact of "hot spot policing" on criminal activity [23]. These researchers were interested in whether a displacement effect (i.e., whether crime simply moves around the corner) occurred as a result of policing tactics.

This particular study is of specific interest in that it empirically tests principles of the crime control model. In their study, Weisburd et al. [23] focus on prostitution and drug sales in two different neighborhoods wherein police crime prevention tactics and strategies were directed in those neighborhoods. In the end, the researchers not only discovered that the targeted criminal activity decreased, it was not displaced to any other nearby location. Moreover, they learned that the policing efforts had a diffusion effect on crime in surrounding areas. Explaining the lack of displacement, Weisburd et al. [23] found that offenders were not motivated to seek out a different location to continue their criminal activity. Clarifying, the offenders interviewed claimed that it would take too much effort and time, there was no established customer base in a new location, they may be treading on another person's turf, and fear of falling victim to violence. The Weisburd et al. [23] study substantiates the efforts of directed crime prevention as an effective means to control crime without displacing it to another location.

\section{The Perris Station}

The Perris Station is one of several patrol stations for the Riverside County Sheriff's Department, located in southern California. In addition to patrolling the unincorporated county area surrounding the station, the Perris Station provides full law enforcement services (e.g., patrol, traffic enforcement (this service is provided to the contracted incorporated cities. The California Highway Patrol provides traffic enforcement and conducts collision investigations for the unincorporated county areas), investigations, special enforcement teams-SET, etc.) to more than 213,000 people and covering approximately 190 square miles. Moreover, this station serves as the Police Department for the incorporated cities of Perris, Menifee, and Canyon Lake.

A review of policing practices prior to 2008 at the Perris Station revealed that patrol operations closely followed the professional model of policing (i.e., reactive policing). Upon closer examination, it became apparent that independently, each unit (i.e., patrol, investigations, traffic, SET) worked fairly well if given a specific task to handle. However, there was little direction beyond responding to calls in a timely manner and investigating crimes after the fact. Furthermore, there was no mechanism in place to share information across or within units. Quite frankly, as a detrimental consequence, there was little effort made to examine emerging crime trends and develop strategies to prevent crime.

To overcome what was arguably a definite shortcoming for delivery of service, in 2008, a strategy, loosely based on the COMPSTAT model, was developed to bridge the gap and establish a means to track crime trends and develop strategies to reduce crime. Staff at the Perris Station established continuity by developing small geographical areas of responsibility (i.e., zones) in which deputies were assigned on a regular basis. In order to limit duplication of effort, and strengthen communication amongst staff members and with other units, a pass-on system for sharing information was devised. This structure ensured that not only did each unit have access to developing trends within a geographical area, but each person assigned to this same area, despite their assignment, had access as well. In conjunction with the pass-on system, deputies assigned to the special enforcement team (SET) were designated as "zone coordinators." Taking a different accountability approach as established in the COMPSTAT model, wherein station or area commanders (i.e., persons of 
higher rank) are held accountable for the results, the Perris Station model followed more of a community-oriented policing philosophy (i.e., entrusting more decision-making authority to the line level deputy) by empowering the zone coordinators (rank of deputy) to develop and employ crime prevention strategies.

Each zone coordinator was tasked with ensuring that crime data (i.e., Part 1 crimes by zone), which was produced biweekly by the station crime analyst, was reviewed through a process of "analysis and response" and provided in a report every two weeks. The report consisted of detailed crime maps for each zone showing "hot spots," tables presenting crime changes over time (i.e., two-week, year-to-date, etc.), and charts demonstrating trends by time of day and day of week. The "analysis" section of the report consisted of describing a particular crime trend for a given crime category such as burglary (e.g., what was occurring-method of operation used by the suspect, similarity among victims, locations and times, who the suspects were if identified, etc.). The "response" section outlined what action was to be taken to minimize or prevent the crime pattern from continuing. Overtime, the analysis and response sections became more refined so as to provide clear direction to the end user (e.g., identifying for the patrol officer assigned to a specific zone the locations to patrol, timeframe in which the criminal activity was occurring, suspects to look for, etc.).

The deputies assigned as the zone coordinators, by way of their assignment, assume much of the responsibility in this model; however, they are provided great freedom to adjust their work schedules as new crime trends emerge in their zones. Additionally, accountability for the results of the crime control strategies used by each zone coordinator is shared amongst their peers, supervisors, the lieutenants and station commander on a biweekly basis. This is accomplished every other week when the stakeholders (i.e., zone coordinators, representative patrol deputies, station supervisors, lieutenants, commander, as well as members from the Investigations Unit, Traffic Unit, Crime Analysis Unit, Gang Task Force and Narcotics Task Force) meet to review the current crime trends. Each person, specifically the supervisors, lieutenants, and commander, is responsible for being familiar with the current trends, strategies, and tactics being used to address the identified crime problems. Although the zone coordinator assumes most of the responsibility for addressing questions delivered from the station's management team, the environment is not meant to be adversarial or contentious. To share in the overall accountability of the results, the Perris Station model strived to encourage the more experienced participants (i.e., supervisors and managers) to help guide and develop crime reduction strategies and tactics.

One of the challenges to research is gaining access to data and being able to conduct empirical evaluation of the effectiveness of a given program. At present, we have a defined period in time in which the Perris Station altered its policing strategy, which offered an opportunity for evaluation. As stated earlier, the purpose of this study was to determine whether the crime control model that was developed at the
Perris Station was effective in reducing crime rates. The study also compares crime rates in Perris to three other cities that did not use such crime control methods. Using the city of Perris as our test case, it is our hypothesis that the crime control model, with its proactive crime prevention strategies and techniques, supports reduction of Part 1 crime (e.g., homicide, robbery, rape, assault, burglary, autotheft, larceny, and arson) as a whole when compared to three control cities (Lake Elsinore, Coachella, and La Quinta).

\section{Methods}

7.1. Data. The Riverside County Sheriff's Department operates ten patrol stations throughout the county, which comprises more than 7,000 square miles, or roughly the size of the state of New Jersey. In 2010, there were 26 cities in the county; 15 of these cities contracted law enforcement services from the Sheriff's Department. For comparison purposes, similar-sized control cities (Lake Elsinore, Coachella and La Quinta) within the Sheriff Department's sphere of influence were sought. Although crime data practices were the same throughout the Department, the control cities had not implemented a defined crime control model as developed by the Perris Station, which made it possible to make this assessment.

Crime data were collected from the Riverside County Sheriff's Department Crime Analysis Unit. Table 1 depicts the total Part 1 crime rate and population for each of the cities, covering each of the 11 years from 2000 through 2010 . Table 2 does the same thing for violent crime (i.e., homicide, robbery, rape, and assault) and property crime (i.e., arson, burglary, theft and autotheft) separately.

For further comparison of the cities, and in support of data presented in Tables 1 and 2 , three graphical presentations were developed to show the various crime trends over the 11-year period. Observation of the total crime rate by city, Figure 1, found that during the 11-year period Perris had the most pronounced decline in total Part 1 crime from 2000 through 2010, more than 45 percent. Part 1 crime for Lake Elsinore was the most stable across time compared to the other cities, ending with an overall decline from 2000 through 2010, nearly 19 percent. La Quinta experienced the sharpest increase in Part 1 crime by 2005 followed by a similar decrease through 2010, realizing a little more than 13 percent decrease overall. Starting with the lowest Part 1 crime rate compared to the other cities, Coachella followed a similar rise and fall in crime as seen in La Quinta; however, the crime decline was less pronounced overall. In fact, over the 11-year period, Coachella experienced an increase in total crime by almost 22 percent.

When examining violent crime alone (i.e., homicide, robbery, rape, and assault), Figure 2, Perris began and ended the 11-year period with the highest rate, but experienced the greatest overall decline in violent crime, more than 53 percent. Lake Elsinore realized a downward trend throughout the study period with the second sharpest decrease; nearly 49 percent. Despite maintaining the overall lowest violent crime rate over the 11-year period, this category of crime 
TABle 1: Population and total Part 1 crime rate for Perris, Lake Elsinore, Coachella, and La Quinta per 10,000 population.

\begin{tabular}{ccccccccc}
\hline Year & Perris crime rate & Perris Pop. & $\begin{array}{c}\text { Lake Elsinore } \\
\text { crime rate }\end{array}$ & $\begin{array}{c}\text { Lake Elsinore } \\
\text { Pop. }\end{array}$ & $\begin{array}{c}\text { Coachella } \\
\text { crime rate }\end{array}$ & Coachella Pop. & $\begin{array}{c}\text { La Quinta } \\
\text { crime rate }\end{array}$ & \begin{tabular}{c} 
La Quinta Pop. \\
\hline 2000
\end{tabular} \\
\hline 572.8 & 36,189 & 462.2 & 28,930 & 379.3 & 22,724 & 456.7 & 23,694 \\
2001 & 524.9 & 39,408 & 447.3 & 29,999 & 423.4 & 23,146 & 599.4 & 25,459 \\
2002 & 525.5 & 42,627 & 484.6 & 31,224 & 533.9 & 23,974 & 539.2 & 27,469 \\
2003 & 507.3 & 45,846 & 473.5 & 33,456 & 469.7 & 26,422 & 602.6 & 28,642 \\
2004 & 479.3 & 49,065 & 480.9 & 35,993 & 651.9 & 27,214 & 652.9 & 30,110 \\
2005 & 539.4 & 52,284 & 458.8 & 38,271 & 558.2 & 29,754 & 731.0 & 32,558 \\
2006 & 535.3 & 55,503 & 459.3 & 41,239 & 615.7 & 33,964 & 660.8 & 33,987 \\
2007 & 506.5 & 58,722 & 411.7 & 47,705 & 526.2 & 36,851 & 534.2 & 35,792 \\
2008 & 423.5 & 61,941 & 424.5 & 49,747 & 528.0 & 38,521 & 502.1 & 36,774 \\
2009 & 369.6 & 65,160 & 400.5 & 50,616 & 429.9 & 39,079 & 489.3 & 37,116 \\
2010 & 312.8 & 68,386 & 375.1 & 51,821 & 461.9 & 40,704 & 396.9 & 37,467 \\
\hline
\end{tabular}

Note: city population was obtained from the California Department of Finance Population Estimates for Cities, Counties, and the State, 2001-2010, with 2000 and 2010 census counts.

TABle 2: Violent and property crime rate for Perris, Lake Elsinore, Coachella, and La Quinta per 10,000 population.

\begin{tabular}{|c|c|c|c|c|c|c|c|c|}
\hline \multirow{2}{*}{ Year } & \multicolumn{4}{|c|}{ Violent crime rate } & \multicolumn{4}{|c|}{ Property crime rate } \\
\hline & Perris & Lake Elsinore & Coachella & La Quinta & Perris & Lake Elsinore & Coachella & La Quinta \\
\hline 2000 & 115.2 & 77.1 & 62.9 & 34.6 & 457.6 & 385.1 & 316.4 & 422.0 \\
\hline 2001 & 98.5 & 66.3 & 60.5 & 32.6 & 426.4 & 381.0 & 362.9 & 566.8 \\
\hline 2002 & 84.8 & 69.8 & 73.4 & 31.3 & 440.7 & 414.7 & 460.5 & 507.8 \\
\hline 2003 & 82.3 & 69.6 & 68.1 & 39.5 & 425.0 & 403.8 & 401.6 & 563.2 \\
\hline 2004 & 74.2 & 53.1 & 62.8 & 34.9 & 405.1 & 427.9 & 589.0 & 618.1 \\
\hline 2005 & 74.6 & 50.4 & 62.2 & 36.6 & 464.8 & 408.4 & 496.1 & 694.5 \\
\hline 2006 & 95.2 & 59.2 & 86.3 & 39.7 & 440.1 & 400.1 & 529.4 & 621.1 \\
\hline 2007 & 85.4 & 43.0 & 73.3 & 36.3 & 421.1 & 368.7 & 452.9 & 497.9 \\
\hline 2008 & 85.2 & 46.0 & 59.7 & 37.3 & 336.1 & 378.5 & 468.3 & 464.8 \\
\hline 2009 & 70.6 & 38.9 & 51.4 & 38.8 & 296.5 & 361.5 & 378.5 & 450.5 \\
\hline 2010 & 54.0 & 39.6 & 51.1 & 36.6 & 258.8 & 335.6 & 410.8 & 360.3 \\
\hline
\end{tabular}

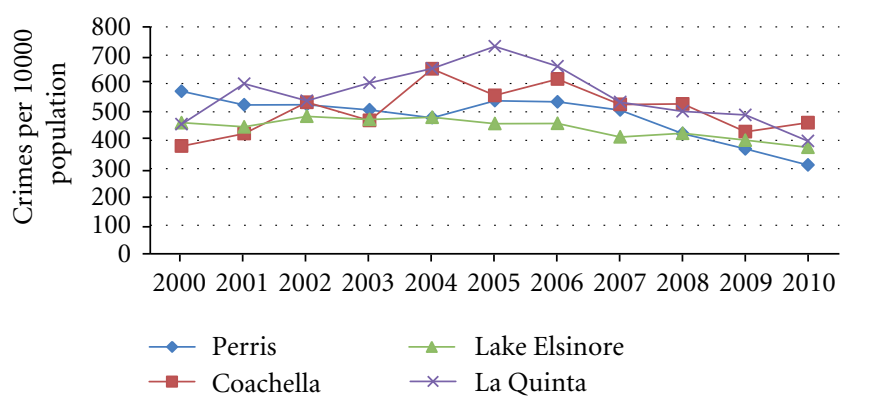

FIGURE 1: Total crime rate by city.

increased by nearly 6 percent in La Quinta. Compared to the other cities, Coachella experienced a rather stable violent crime rate for the first several years, spiking by the mid-2000s then declining by 2010 with an overall decrease of nearly 19 percent.

The final graphic presentation is found in Figure 3, depicting a comparison of the cities' property crime rate (i.e.,

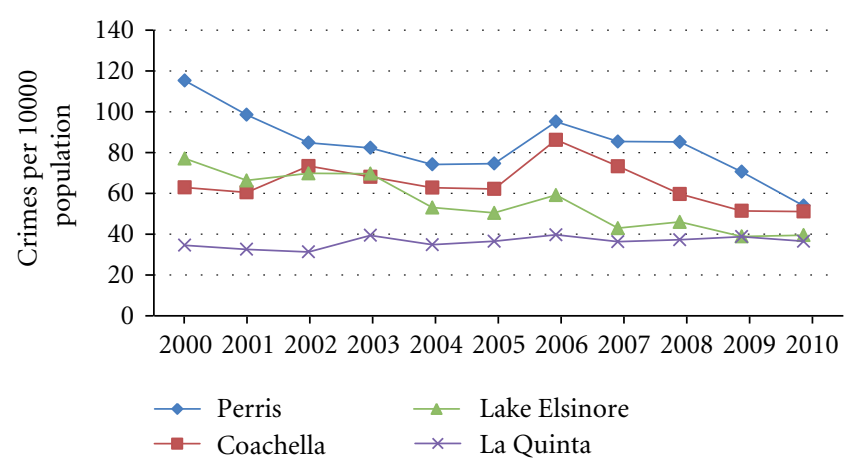

FIGURE 2: Violent crime rate by city.

burglary, theft, vehicle theft, and arson). Again, beginning with the highest crime rate, but this time ending with the lowest and sharpest decrease, it was Perris with more than 43 percent reduction. As seen in the comparison of total crime rate, Lake Elsinore maintained the most stable property crime rate over time with a total decrease of nearly 13 


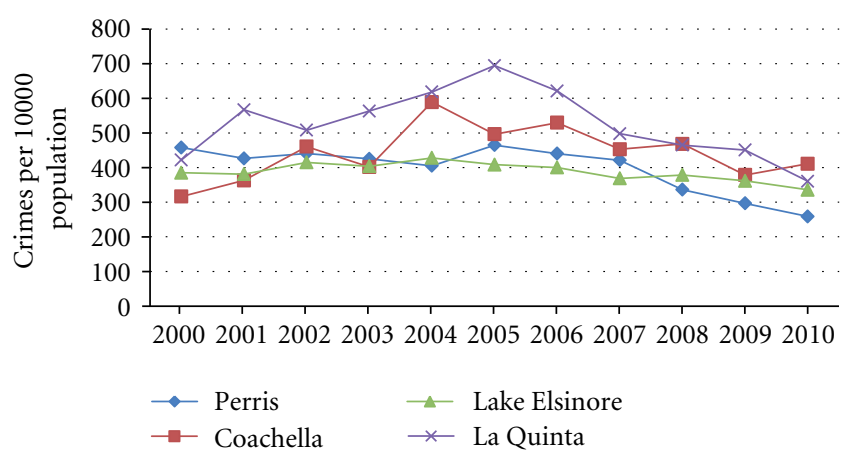

Figure 3: Property crime rate by city.

percent by the end of 2010. Although more radical through the 11-year period, rising and falling, La Quinta finished with approximately 15 percent decrease. Beginning with the lowest property crime rate and ending with the highest was Coachella. Property crime increased and decreased over the 11-year period for Coachella, ending with an overall increase by nearly 30 percent. This crime category certainly accounts for the increase in total Part 1 crime rate for Coachella as well.

7.2. Estimation. The data utilized are in the form of time series for Perris and the control cities. The use of OLS as an estimating technique presents a potential problem as the errors may not be independent of each other, a situation that violates classical linear regression assumptions of homoscedasticity and uncorrelated disturbances. Using ordinary regression might therefore lead to inefficient estimates and lack of confidence in statistical testing. The BoxJenkins [24] approach to time series is quite popular, but one of its primary limitations is that an analyst requires far more data points in order to derive meaningful estimates [25]. Convergence problems are frequent with historical data points below $50[25,26]$. Given the limited number of data points (series) in the present study, an autoregressive error correction approach was adopted that removes serial correlation and produces reliable estimates [25, 27, 28]. Analysis began with a simple autoregressive error correction model that specified the crime rate as a function of time trend as follows:

$$
Y_{t}=a+b_{1} \text { time }+e_{t}
$$

where

$$
e_{t}=\rho e_{t-1}+v_{t}
$$

Subsequent analyses then are built on this starting model, using the AUTOREG procedure in SAS 9.3 [28]. Due to the rather small number of cases and the exploratory nature of the study, an $\alpha$ value of 0.10 was used for hypothesis testing.

\section{Results}

Initial analysis of the effect of time on Part I crimes in the city of Perris alone, using OLS, showed a considerable amount of serial correlation among the errors. The DurbinWatson statistic was $0.687(P=.000)$ indicating positive autocorrelation. To correct the problem, the model was reestimated using Maximum likelihood that entailed including an autoregressive parameter in the equation using the NLAG option in PROC AUTOREG. Relevant results of the corrected model are shown in Table 3, Model 1. As may be seen in Model 1, over time, Part 1 crime rates declined in Perris $(b=-23.372, t=-3.27 ; P=.005)$.

The primary independent variable, the crime control program, was introduced next into the analysis. It was dummycoded as follows: there was 0 for years before program implementation and 1 for years after the program was in effect. Relevant results of the analysis following correction for serial correlation are presented in Model 2.

As may be seen in Model 2, time continued to reduce Part 1 crimes, though its effect was reduced from the previous model (Model 1). The crime control model (i.e., the intervention) was significantly associated with Part 1 crimes $(b=-90.119, t=-2.13, P=.035)$, indicating a difference in Part 1 crime decline by over 90.1 points after program implementation, taking into account the impact of time. The total $R$-square was moderately high $\left(R^{2}=0.864\right)$. The next stage of the analysis involved bringing in the control cities, that is, those that did not have the specific crime intervention model used in Perris. Pooling data from all cities increased the sample size from 11 to 44. Results are shown in Model 3).

As seen in Model 3, time lost statistical significance, though it remained in the negative direction. The only variable that was significant was the crime control model. No other city experienced significant increases or decreases in Part 1 crime rates compared to Perris.

In order to determine whether the crime control model initiative may have been more effective for certain types of crime than others, the total crime rate was divided into two categories-property crimes and violent crimes. In addition, given that four cities are in the analysis, each was dummycoded and included in the analysis to serve as controls and minimize the risk of making false inferences.

Model 4 shows results of autoregressive time series analysis of the effect of the crime control model on property crimes, controlled for time, and the three cities that did not employ the crime control model. Perris, which had the program, was used as the reference category. As may be seen, year (time) was not significant, following correction for serial correlation, although the coefficient remained in the negative direction. Years following the introduction of the crime control model had lower property crime rates than those preceding it. The effect of the control cities did not reach statistical significance.

The final model focused on violent crimes to determine whether the crime control model initiative was effective. Relevant autoregressive parameter estimates are shown in Model 5. As illustrated in Model 5, time reduced violent crime rates $(b=-2.314, t=-4.05)$. The crime control model program, however, had no effect on violent crime rates. In addition, the cities without the program experienced significantly lower violent crime rates during the period than Perris. 
TABLE 3: Autoregressive corrected models.

\begin{tabular}{|c|c|c|c|}
\hline Variable & $\beta$ & $t$ & Probability \\
\hline \multicolumn{4}{|c|}{ Model 1-effect of time on Part I crimes, city of Perris } \\
\hline Year & -23.372 & -3.27 & .005 \\
\hline Intercept & 47333 & & \\
\hline Total $R$-square & 0.804 & & \\
\hline Regress $R$-square & 0.572 & & \\
\hline Log likelihood & -54.614 & & \\
\hline Durbin-Watson $d$ & 1.681 & & 0.371 \\
\hline$N$ & 11 & & \\
\hline \multicolumn{4}{|c|}{ Model 2-effect of the crime control model on Part I crimes, city of Perris } \\
\hline Year & -11.922 & -1.83 & .055 \\
\hline Crime control $(1=$ yes $)$ & -90.119 & -2.13 & .035 \\
\hline Intercept & 24407 & & \\
\hline Total $R$-square & 0.864 & & \\
\hline Regress $R$-square & 0.784 & & \\
\hline Log likelihood & -52.421 & & \\
\hline Durbin-Watson $d$ & 1.925 & & 0.475 \\
\hline$N$ & 11 & & \\
\hline \multicolumn{4}{|c|}{ Model 3-effect of the crime control model on Part 1 crimes, controlling for time and other cities } \\
\hline Year (time) & -3.790 & -0.91 & .185 \\
\hline Crime control $(1=$ yes $)$ & -89.403 & -1.49 & .072 \\
\hline Perris & Reference & & \\
\hline Coachella & -23.811 & -0.44 & .329 \\
\hline Lake Elsinore & -65.202 & -1.20 & .119 \\
\hline La Quinta & 16.234 & 0.29 & .386 \\
\hline Intercept & 8119 & & \\
\hline Total $R$-square & 0.573 & & \\
\hline Regress $R$-square & 0.192 & & \\
\hline Log likelihood & -239.799 & & \\
\hline Durbin-Watson $d$ & 2.006 & & 0.327 \\
\hline$N$ & 44 & & \\
\hline
\end{tabular}

Model 4-effect of the crime control model on property crimes, controlling for time and other cities

\begin{tabular}{lccc}
\hline Year (time) & -1.400 & -0.36 & .358 \\
Crime control $(1=$ yes $)$ & -87.026 & -1.51 & .069 \\
Perris & Reference & & .0 .05 \\
Coachella & -2.319 & -0.74 & .232 \\
Lake Elsinore & -38.791 & 1.22 & .115 \\
La Quinta & 65.477 & & \\
Intercept & 3241 & & \\
Total $R$-square & 0.624 & & \\
Regress $R$-square & 0.219 & & 0.300 \\
Log likelihood & -238.164 & & \\
Durbin-Watson $d$ & 1.984 & & \\
$N$ & 44 & & \\
\hline
\end{tabular}


TABLE 3: Continued.

\begin{tabular}{lccr}
\hline Variable & $\beta$ & $t$ & \multicolumn{1}{c}{ Probability } \\
\hline Year (time) & Model 5-effect of the crime control model on violent crimes, controlling for time and other cities \\
Crime control $(1=$ yes $)$ & -2.314 & -4.05 & .000 \\
Perris & -4.293 & -0.50 & .309 \\
Coachella & Reference & & .2 .97 \\
Lake Elsinore & -22.134 & -3.57 & .002 \\
La Quinta & -27.050 & -6.44 & .000 \\
Intercept & -49.668 & & .000 \\
Total $R$-square & 4726 & \\
Regress $R$-square & 0.843 & & \\
Log likelihood & 0.600 & & 0.342 \\
Durbin-Watson $d$ & -154.565 & & \\
$N$ & 1.950 & 44 & \\
\hline
\end{tabular}

Note: statistical tests are 1-tailed, and $\alpha=.10$ for tests of regression coefficients.

\section{Discussion}

As other researchers have pointed out, there is little empirical research on COMPSTAT or other similar crime control models [17]. The authors point out "those studies that do exist tend to be brief, rely heavily on anecdotal evidence, or concentrate on the nation's largest, and, by any measure, most exceptional police department, the NYPD" (p. 465). In fact, with few exceptions, much that is written tends to describe the principles and methods behind the COMPSTAT model as opposed to testing the effectiveness of the model by comparing crime data before and after implementation of the conceptual policing model or testing it against controls (i.e., comparable cities that did not employ the same policing strategy). In one case in which researchers examined the effects of COMPSTAT on New York City homicides, they found no significant change in reported incidents when compared to other cities [14] despite other researchers claiming evidence that the COMPSTAT model of policing reduced violent crime in New York City [29]. Furthermore, in another location and under different circumstances, but exploring the effectiveness of a version of the crime control model, other researchers found that when the police employ well-defined crime prevention strategies and tactics, they experienced a reduction in crime with no evidence of displacement [30].

Given the few number of empirical studies that examine whether the crime control model effectively does what it conceptually claims to do, the present study was undertaken to investigate the effectiveness of the crime control model as implemented at the Riverside County Sheriff's Department, Perris Station, in the city of Perris and compared to three control cities. Here, we would note that it should be generally understood that that every law enforcement agency would commonly have within their mission to minimize crime; however, the manner in which a police department goes about doing so may depend on management philosophy, resources, and knowledge of best practices.

While crime trends may have been decreasing for some of the cities in this study prior to 2008 (Perris being one of them), evidence indicates that the crime control model, as applied in the city of Perris, accelerated the crime decrease in the subsequent years. Because of the prior trend, it would be overly optimistic, without further analysis and evidence, to assert that the crime control model caused the decrease in the following years. However, relying collectively upon several factors, one can deduce that there is a relationship between the enhanced crime decrease and the policing strategies employed in the city of Perris. First, when examining the crime trends over time (Figures 1, 2, and 3), we find that Perris and Lake Elsinore were the only cities to experience a crime rate decrease for total, violent and property crimes during the 11-year period; Coachella's total and property crime rates increased (we acknowledge that the increase in property crime rate is simultaneously inflating the total crime rate here), and the violent crime rate rose in the city of La Quinta. Further, when comparing the decrease in crime rates for Perris and Lake Elsinore, the rate of decrease was greatest for Perris across each crime category. Respectively, the crime rate decreased in Perris 45 percent, 53 percent, and 43 percent for total, violent, and property crimes, whereas the decrease in Lake Elsinore was 19 percent, 49 percent, and 13 percent.

Further evidence of program effectiveness was seen in Table 3, Models 1 and 2, which concentrated on Perris alone. It was found that the crime rates declined substantially in the years following the implementation of the crime control model. Even after controlling for other cities that did not introduce the program (Model 3), it was observed that years following the execution of the model in Perris still showed reduction of total crime rates.

Analysis also showed that perhaps researchers investigating program effectiveness (e.g., COMPSTAT) need to disaggregate crimes by specific types. We found that in Perris, while the program worked for total and property crimes, it was less effective with regard to violent crimes as seen in Models 4 and 5. Before definitive conclusions can be drawn, given the fact that the coefficients were all in the negative direction, there is evidence to suggest that programs such as 
the one evaluated in this study may become more effective with time.

Despite the value of this study, there were some limitations. The first limitation was briefly discussed above regarding the short duration of time in which the model has been operating. Under better circumstances, we would have more data (i.e., years) to examine; however, as is the nature with examining the effectiveness of various programs, time might not always work in favor of the research. In the end, we need to take advantage of each research opportunity as they arise and make the best of them.

Another limitation was that despite our best effort to make a cautious comparison with other similar cities, it was difficult to provide a direct assessment of crime differences or similarities because each city tends to be diverse in a number of ways that make such a comparison nearly impossible, if not impractical. In fact, the FBI cautions against making this type of comparison [31]. Thus, to attribute any decreases in crime to one factor such as the implementation of a specified crime control program would be overreaching. Ideally, we would have liked to have had more control variables in the analysis such as unemployment, household size, state and local economic performance and more specific population demographics, but such data were not available. Even if they were, the sample size for each city was limited.

A third limitation to the study lies within the complexity of the crime control model itself. While we maintain that our analysis indicated that the crime control strategies developed in Perris accelerated the crime decrease in the city as compared to the control cities, more research is necessary to more narrowly define what it is about the model that is most effective. Notwithstanding what we have learned in the present study, much remains unknown. To still be determined is what specific component found within the crime control model produced or contributed to the crime decline experienced in Perris. Could it be the data collection and analysis, the accountability and ownership of a geographic area by the zone coordinator deputies, the strategic review process with police administration and line-level stakeholders, or some combination of strategies? Further research could help answer this question and prove informative to police agencies interested in implementing a similar program.

In spite of the limitations observed above, findings support the argument that the manner in which police officers are deployed matters (i.e., the implemented crime control model in Perris); police can be more effective when their efforts are strategically directed at identified crime trends. Although it can be argued that any type of policing reform implemented at the Perris Station could have resulted in a decrease in crime, this study focused on a specific model. As such, our study adds to the research that the police, as demonstrated through the benefits of the crime control model, can in fact reduce and prevent crime based on the model's principles of gathering and tracking current crime data, sharing information, and employing strategic policing methods. Analyses provide evidence to suggest that strategic policing models (e.g., COMPSTAT, hot spot policing, etc.) may be more effective than reactive policing methods. In an ever diminishing environment for police funding, police departments may find value by investing in a crime control model as opposed to employing the principles of the professional model, which is based on rapid response, random patrols, and reactive investigations.

\section{References}

[1] W. F. Walsh and G. F. Vito, "The meaning of Compstat: analysis and response," Journal of Contemporary Criminal Justice, vol. 20, pp. 51-68, 2004.

[2] S. J. Gaffigan, Understanding Community Policing: A Framework For Action [Monograph], Bureau of Justice Assistance, Department of Justice, Office of Justice Programs, National Institute of Justice, Washington, DC, USA, 1994.

[3] H. Goldstein, Problem-Oriented Policing, McGraw-Hill, New York, NY, USA, 1990.

[4] P. McDonald, Managing Police Operations: Implementing the NYPD Crime Control Model Using COMPSTAT, Wadsworth Publishing, Belmont, Mass, USA, 2002.

[5] B. J. Palombo, "History of the professional-ization of law enforcement," in Academic Professionalism in Law Enforcement, B. J. Palombo, Ed., Chapter 2, pp. 25-72, Garland, New York, NY, USA, 1995.

[6] J. H. Skolnick and J. J. Fyfe, Above the Law: Police and the Excessive Use of Force, The Free Press, New York, NY, USA, 1993.

[7] W. J. Bratton and S. W. Malinowski, "Police performance management in practice: taking COMPSTAT to the next level," Policing, vol. 2, pp. 259-265, 2008.

[8] J. S. Magers, "Compstat: a new paradigm for policing or a repudiation of community policing?" Journal of Contemporary Criminal Justice, vol. 20, pp. 70-79, 2004.

[9] P. McDonald, "COP, COMSTAT, and the new professionalism: mutual support or counterproductivity," in Critical Issues in Policing, R. G. Dunham and G. D. Alpert, Eds., pp. 255-277, Prospect Heights, 2001.

[10] D. Weisburd, S. D. Mastrofski, A. M. McNally, R. Greenspan, and J. J. Willis, "Reforming to preserve: compstat and strategic problem solving in American policing," Criminology \& Public Policy, vol. 2, pp. 421-456, 2003.

[11] S. Sadd and R. M. Grinc, Implementation Challenges in Community Policing: Innovative Neighborhood-Oriented Policing in Eight Cities, Department of Justice, Office of Justice Programs, National Institute of Justice, Washington, DC, USA, 1996.

[12] W. J. Bratton, "Research: a practitioner's perspective, from the streets: keynote speech as delivered at the 2006 National Institute of Justice Conference on July 17, 2006," Western Criminology Review, vol. 7, no. 3, pp. 1-6, 2006.

[13] G. L. Kelling and W. J. Bratton, "Declining crime rates: Insiders' views of the New York City story," Journal of Criminal Law and Criminology, vol. 88, no. 4, p. 1217, 1998.

[14] R. Rosenfeld, R. Fornango, and E. Baumer, "Did ceasefire, Compstat, and exile reduce homicide?" Criminology \& Public Policy, vol. 4, pp. 419-449, 2005.

[15] W. J. Bratton, "Cutting crime and restoring order: what America can learn from New Yorks finest. Heritage lecture \#573," The Heritage Foundation Leadership for America, 1996, http://www.heritage.org /research/crime/hl573.cfm. 
[16] G. L. Kelling, T. Pate, D. Dieckman, and C. E. Brown, The Kansas City Preventive Patrol Experiment: A Summary Report, Police Foundation, Washington, DC, USA, 2003.

[17] J. J. Willis, S. D. Mastrofski, and D. Weisburd, "COMPSTAT and bureaucracy: a case study of challenges and opportunities for change," Justice Quarterly, vol. 21, no. 3, pp. 463-496, 2004.

[18] G. F. Vito, W. F. Walsh, and J. Kunselman, "Compstat: the manager's perspective," International Journal of Police Science \& Management, vol. 7, pp. 187-196, 2004.

[19] M. Long, S. Hallam, and E. B. Silverman, "The Anglo-American measurement of police performance: compstat and best value," British Journal of Community Justice, vol. 3, pp. 45-59, 2005.

[20] J. Shane, Compstat Implementation, FBI Law Enforcement Bulletin, 2004.

[21] V. E. Henry, The COMPSTAT Paradigm: Management Accountability in Policing, Business and the Public Sector, Looseleaf Law Publications, Flushing, NY, USA, 2003.

[22] L. E. Cohen and M. Felson, "Social change and crime rate trends: a routine activity approach," American Sociological Review, vol. 44, pp. 588-605, 1979.

[23] D. Weisburd, L. A. Wyckoff, J. Ready, J. E. Eck, J. C. Hinkle, and F. Gajewski, "Does crime just move around the corner? A controlled study of spatial displacement and diffusion of crime control benefits," Criminology, vol. 44, no. 3, pp. 549-591, 2006.

[24] G. E. P. Box and G. M. Jenkins, Time Series Analysis Forecasting and Control, Holden Day, Oakland, Calif, USA, 1976.

[25] R. Yaffee, Introduction to Time Series Analysis and Forecasting, Academic Press, San Diego, Calif, USA, 2000.

[26] R. McCleary, R. Hay, E. E. Merdinger, and D. McDowell, Applied Time Series Analysis for the Social Sciences, Sage, Thousand Oaks, Calif, USA, 1980.

[27] P. J. Diggle, Time Series: A Biostatistical Introduction, Clarendon Press, London, UK, 1990.

[28] SAS Institute, SAS/ETS: The AUTOREG Procedure [Computer Software Version 9. 3], SAS Institute, Cary, NC, USA, 2010.

[29] G. L. Kelling and W. H. Sousa, "Do police matter? An analysis of the impact of New York Citys Police reforms," Manhattan Institute Civic Report, 2001, http://www.manhattaninstitute.org/pdf/cr_22.pdf.

[30] A. A. Braga and B. J. Bond, "Policing crime and disorder hot spots: a randomized controlled trial," Criminology, vol. 46, no. 3, pp. 577-607, 2008.

[31] United States Department of Justice, Federal Bureau of Investigation, "Crime in the United States," 2011, http:// www.fbi.gov/about-us/cjis/ucr/crime-in-the-u.s/2010/crimein-the-u.s.2010/caution-against-ranking. 

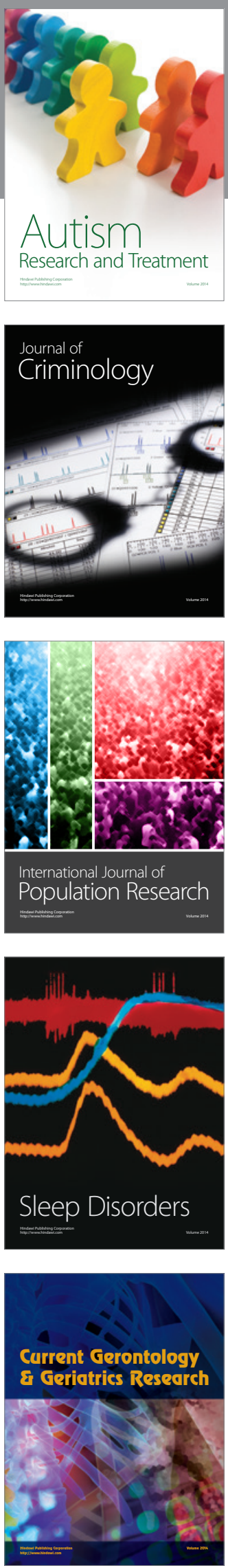
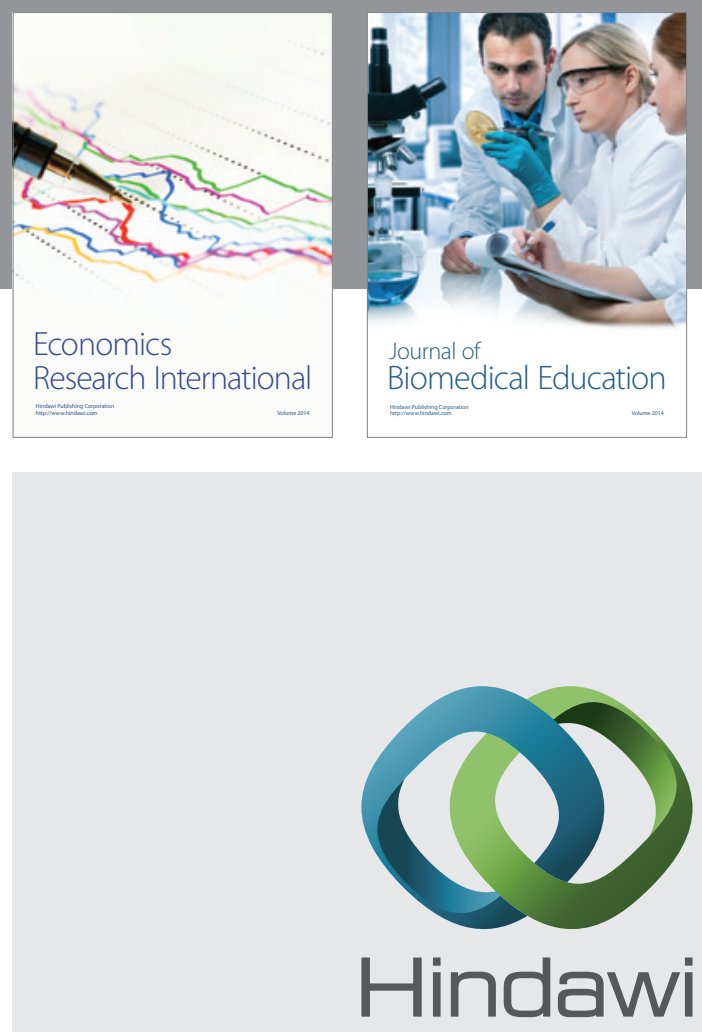

Submit your manuscripts at

http://www.hindawi.com
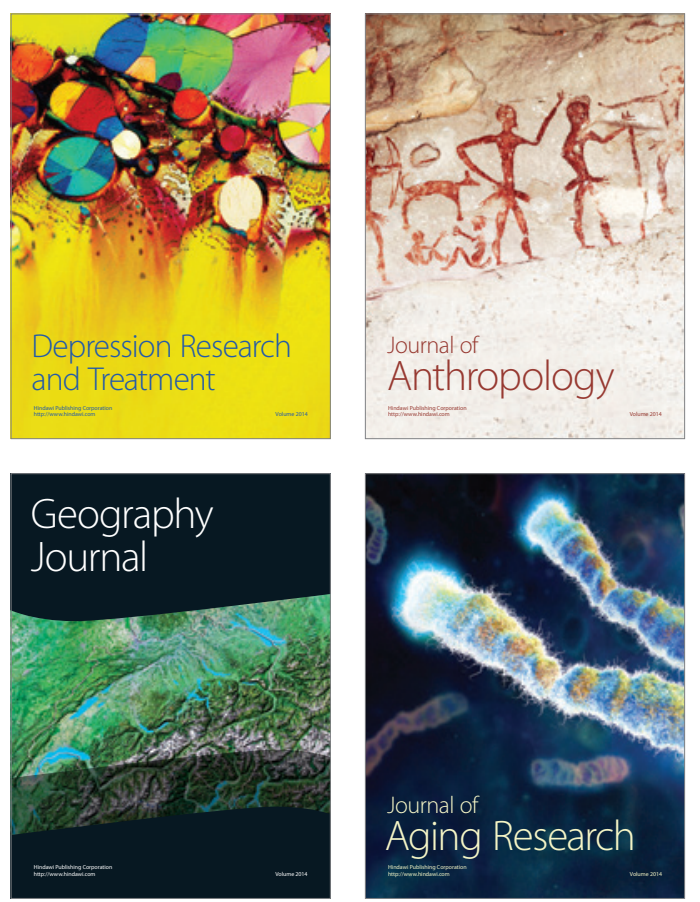
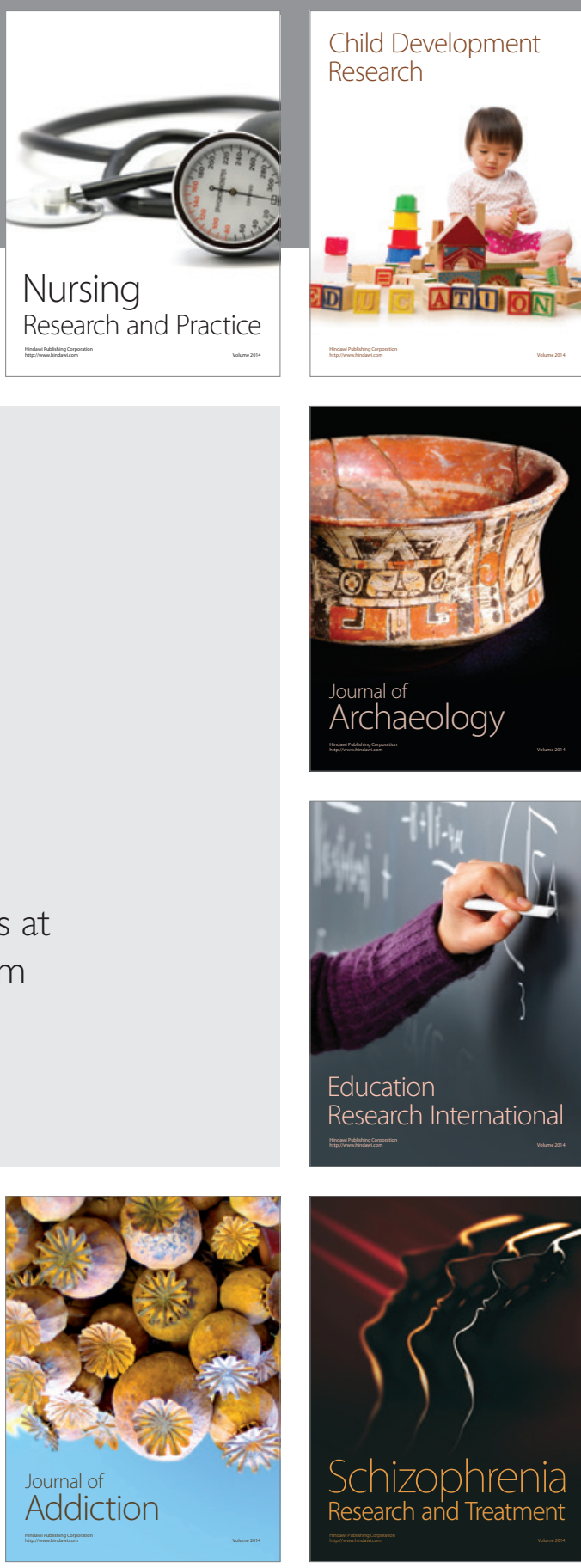

(D)
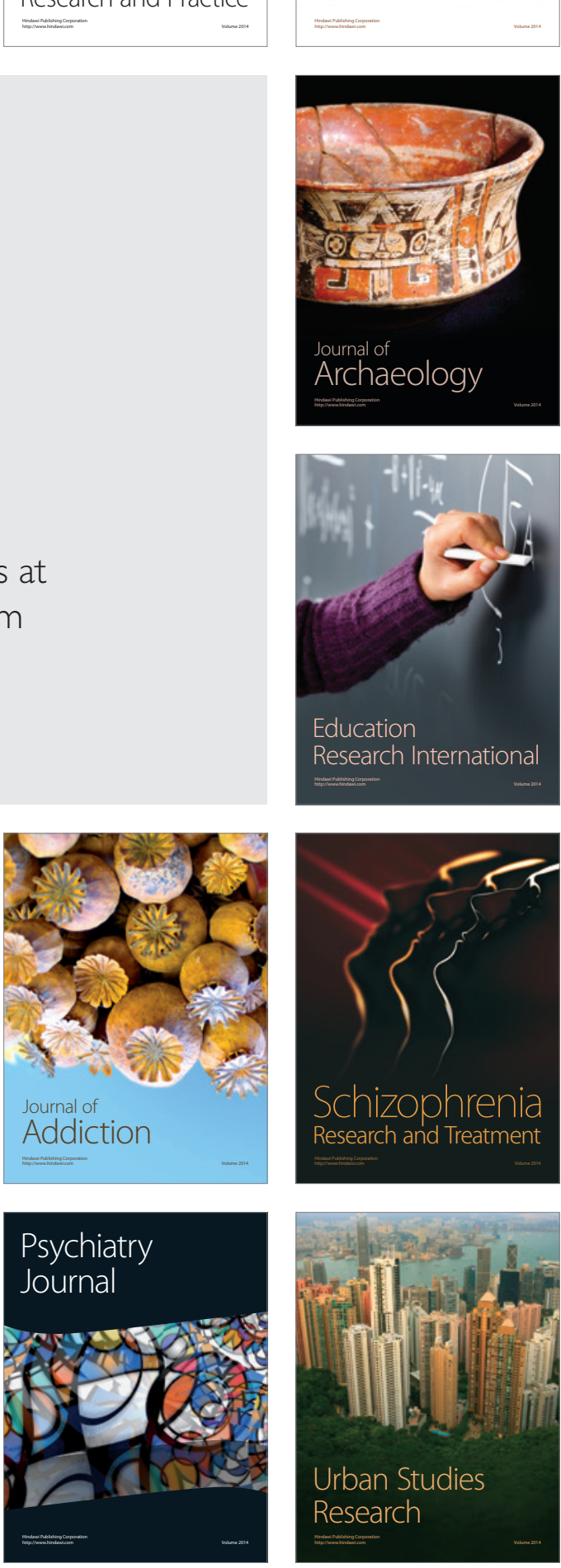